\title{
Novos táxons neotropicais em Acanthocinini (Coleoptera, Cerambycidae)
}

\author{
Miguel A. Monné1 \\ ${ }^{1}$ Museu Nacional, Universidade Federal do Rio de Janeiro, Quinta da Boa Vista, São Cristóvão, 20940-040 Rio de Janeiro-RJ, Brasil. \\ Bolsista do CNPq.

\begin{abstract}
New neotropical taxa in Acanthocinini (Coleoptera, Cerambycidae). The following new taxa are described and figured; from Colombia and Ecuador: Tropidocoleus gen. nov., type species T. bicarinatus sp. nov., Parabaryssinus gen. nov., type species P. lineaticollis (Gounelle, 1910), comb. nov., from Ecuador: Odontozineus gen. nov., type species $O$. penicillatus sp. nov., from Bolivia: Tropidozineus albidus sp. nov. and Nyssodrysternum cingillum sp. nov.; from Brazil (Bahia, Minas Gerais, Rio de Janeiro): Tropidozineus martinsi sp. nov.
\end{abstract}

KEYWORDS. Lamiinae; new combination; taxonomy.

RESUMO. Novos táxons neotropicais em Acanthocinini (Coleoptera, Cerambycidae). São descritos e figurados os novos táxons da Colômbia e Equador: Tropidocoleus gen. nov., espécie-tipo, T. bicarinatus sp. nov., Parabaryssinus gen. nov., espécie-tipo, P. lineaticollis (Gounelle, 1910), comb. nov.; do Equador: Odontozineus gen. nov., espécie-tipo, $O$. penicillatus sp. nov.; da Bolívia: Tropidozineus albidus sp. nov. e Nyssodrysternum cingillum sp. nov.; do Brasil (Bahia, Minas Gerais, Rio de Janeiro): Tropidozineus martinsi sp. nov.

PALAVRAS-CHAVE. Lamiinae; nova combinação; taxonomia.

Continuando o estudo dos Acanthocinini neotropicais, descrevo diversos táxons inéditos e efetuo nova combinação, com base em material das instituições mencionadas a seguir: ACMT, American Coleoptera Museum, San Antonio, Texas, Estados Unidos; CNCI, Canadian National Collection of Insects, Ottawa, Canada; MNKM, Museo de Historia Natural Noel Kempff Mercado, Santa Cruz, Bolívia; MNRJ, Museu Nacional, Universidade Federal do Rio de Janeiro, Rio de Janeiro, Brasil; MZSP, Museu de Zoologia, Universidade de São Paulo, São Paulo, Brasil.

\section{Tropidocoleus gen. nov.}

Etimologia. Tropido $=$ carenas ou quilha + coleus $=$ élitros. Alusivo às carenas dos élitros.

Espécie-tipo, Tropidocoleus bicarinatus sp. nov.

Lobos superiores dos olhos estreitos e afastados entre si, distância entre lobos aproximadamente cinco vezes o diâmetro de um lobo; lobos inferiores subiguais em largura às genas. Antenas com 11 artículos; escapo alongado, sem modificações, o ápice ultrapassa a borda posterior do pronoto. Antenômero III o mais longo, uma vez e 1/4 mais longo que o IV ou o escapo, V-XI gradualmente mais curtos. Protórax 1/3 mais longo que largo, com tubérculo lateral mediano, cônico, o ápice levemente voltado para cima. Pronoto com uma bossa rasa a cada lado do meio. Processo prosternal plano, com largura igual a $3 / 4$ do diâmetro de uma procoxa; processo mesosternal com largura igual ao diâmetro de uma mesocoxa.

Élitros sem cerdas eretas e sem carenas laterais; aproximadamente 4,5 vezes o comprimento do protórax; úmeros protuberantes com a borda anterior arredondada. Crista centro- basal proeminente, arredondada e sem cerdas eretas. Em cada élitro duas carenas longitudinais dorsais nitidamente demarcadas, a interna da borda posterior da crista centro-basal até o espinho ápico-externo e a externa do úmero até o início do quarto apical. Fêmures robustos, profêmures globosos, meso- e metafêmures com curto pedúnculo e fortemente clavados. Metatarsômero I tão longo quanto os seguintes reunidos.

Discussão. Tropidocoleus gen. nov. pertence ao grupo de gêneros com élitros sem cerdas eretas, com crista centro-basal, sem carenas laterais e com carenas dorsais. Neste grupo situam-se Cobelura Erichson, 1847 e o Grupo I (Bates 1863: 105) de Nealcidion Monné, 1977, com carenas dorsais nos élitros, das cristas centro-basais até o ângulo externo dos ápices. Separa-se de ambos pelos lados do protórax com tubérculo mediano proeminente e pela presença de duas carenas dorsais em cada élitro; em Cobelura os lados do protórax são arredondados e em Nealcidion ou são arredondados ou com uma intumescência pouco desenvolvida, além disso ambos os gêneros mencionados possuem uma carena dorsal em cada élitro.

\section{Tropidocoleus bicarinatus sp. nov.} (Figs. 1, 2)

Etimologia. Bicarinatus alusivo às duas carenas elitrais.

Fêmea. Tegumento castanho-escuro. Pubescência predominantemente acinzentada; a pubescência castanhoescura reveste, no pronoto, uma estreita faixa longitudinal a cada lado meio, nos élitros, as cristas centro-basais e máculas 
arredondadas esparsas em toda a superfície,os ápices das tíbias e os tarsos. Abdômen com o centro dos urosternitos glabro.

As antenas apenas atingem o ápice dos élitros, com cerdas curtas e muito esparsas na face interna dos antenômeros basais. Pronoto com pontos grossos, mais densos juntos às margens anterior e posterior. Ápices dos élitros obliquamente chanfrados, ângulo externo projetado em espinho aguçado. Pontos grossos, profundos e densos em toda a superfície elitral. Últimos urotergito e urosternito semicircularmente chanfrados, com os ângulos projetados em curto espinho na extremidade distal.

Macho. As antenas alcançam os ápices dos élitros na extremidade do antenômero IX; últimos urotergito e urosternito transversalmente truncados.

Dimensões em mm, macho/fêmea. Comprimento total, 13,0/ 12,0; comprimento do protórax, 2,0/1,8; maior largura do protórax, 3,0/2,8; comprimento do élitro, 9,5/9,0; largura umeral, $4,0 / 3,5$.

Holótipo fêmea, Colômbia, Santander: $12 \mathrm{~km}$ W Berlin, 10.VII.1982, Clark \& Cave col. (MNRJ). Parátipo macho, Equador, Cotopaxi: Pílalo, 1800 m, X.1977, L. Peña col. (MNRJ).

\section{Odontozineus gen. nov.}

Etimologia. Odonto referente ao dente na antena + Ozineus. Espécie-tipo, Odontozineus penicillatus sp. nov.

Lobos superiores dos olhos tão distantes entre si quanto o diâmetro de um lobo. Sulco interocular profundo e longitudinal. Lobos inferiores subquadrados, uma vez e meia mais longos que as genas. Antenas com onze artículos. Escapo alongado, o ápice ultrapassa a margem posterior do pronoto; antenômero III o mais longo, armado com projeção dentiforme na extremidade ápico-interna (fig. 5); antenômeros IV ao XI gradualmente mais curtos. Protórax quase tão largo quanto longo, com os lados regularmente arredondados, estreitado antes das margens anterior e posterior. Pronoto com duas elevações rasas centro-medianas. Processos pro- e mesosternal planos, com $3 / 4$ do diâmetro de uma procoxa ou de uma mesocoxa, respectivamente.

Élitros com úmeros arredondados, não projetados anteriormente; sem cerdas e sem carenas laterais. Crista centrobasal ornada com um longo tufo de pêlos eretos (fig. 4). Terço basal com fileiras longitudinais de grânulos moderadamente elevados, cada grânulo situado na margem anterior de um ponto. Extremidades obliquamente chanfradas, ângulo externo projetado em espinho curto e aguçado.

Fêmures fortemente pedunculado-clavados; protíbias com dilatação ápico-interna. Metatarsômero I apenas mais longo que os dois seguintes reunidos. Últimos urotergito e urosternito com a margem apical subtruncada.

Discussão. Entre os gêneros com élitros sem cerdas eretas ou semidecumbentes, sem carenas e com crista centro-basal, com o processo mesosternal sem tubérculo, os antenômeros lineares e o antenômero III com espinho ápico-interno nos machos, Odontozineus aproxima-se de Amniscites Gimour, 1957, Alcathousiella Monné, 2005, Alcathousites Gilmour, 1962 e Xenocona Gilmour, 1960. Separa-se de Amniscites principalmente pelo aspecto da crista centro-basal dos élitros, em forma de pincel, com longas cerdas eretas; em Amniscites a crista centro-basal e transversal e ornada com curtas cerdas eretas. Difere de Alcathousiella pelo escapo não dilatado na extremidade e sem espinho apical e pela superfície elitral sem tubérculos manifestos. Em Alcathousiella o escapo é dilatado no terço apical e com espinho distal e a superfície dos élitros além de ser irregular, apresenta tubérculos manifestos. Difere de Alcathousites e Xenocona pelo protórax sem tubérculos laterais e pela largura dos processos pro- e mesosternal, com $3 / 4$ do diâmetro de uma pro- ou mesocoxa respectivamente. Em Alcathousites e Xenocona o protórax é tuberculado nos lados e os processos apenas alcançam o diâmetro de $1 / 4$ de uma proou mesocoxa.

\section{Odontozineus penicillatus sp. nov.} (Figs. 3-5)

Etimologia. Penicillatus, referente à crista centro-basal com aspecto de pincel.

Macho. Tegumento castanho-amarelado, exceto na cabeça, protórax e manchas na metade basal dos élitros, castanhoescuros. Pilosidade predominantemente castanho-amarelada. Lados do protórax e pronoto e faixa mediana transversal em forma de "V" nos élitros, revestidas de densa pilosidade esbranquiçada. A pubescência castanho-escura recobre a cabeça, o centro do pronoto e três manchas longitudinais em cada élitro, a mais interna na sutura, atrás do escutelo, a segunda da base até o fim do quarto basal, circundando a crista centrobasal e a terceira na metade anterior das epipleuras.

Antenas com artículos quase destituídos de cerdas; alcançam os ápices dos élitros aproximadamente no ápice do antenômero V. Pronoto com uma fileira de pontos junto às margens anterior e posterior. Élitros com pontuação alinhada e granuliforme na metade anterior; metade posterior com pontos finos superficiais, regularmente distribuídos.

Dimensões em mm, macho. Comprimento total, 10,0; comprimento do protórax, 2,0; maior largura do protórax, 2, 3; comprimento do élitro, 6,8; largura umeral, 4,0.

Material-tipo. Holótipo macho, Equador, Napo: Lago Agrio, IXX.1977, J. Escobar col. (MNRJ).

\section{Parabaryssinus gen. nov.}

Etimologia. Para, alusivo à semelhança com Baryssinus. Espécie-tipo, Cleodoxus lineaticollis Gounelle, 1910

Lobos superiores dos olhos estreitos, tão distantes entre si quanto cinco vezes o diâmetro de um lobo; lobos inferiores subiguais às genas. Antenas com 11 artículos, sem modificações, o ápice do escapo alcança o tubérculo lateral 


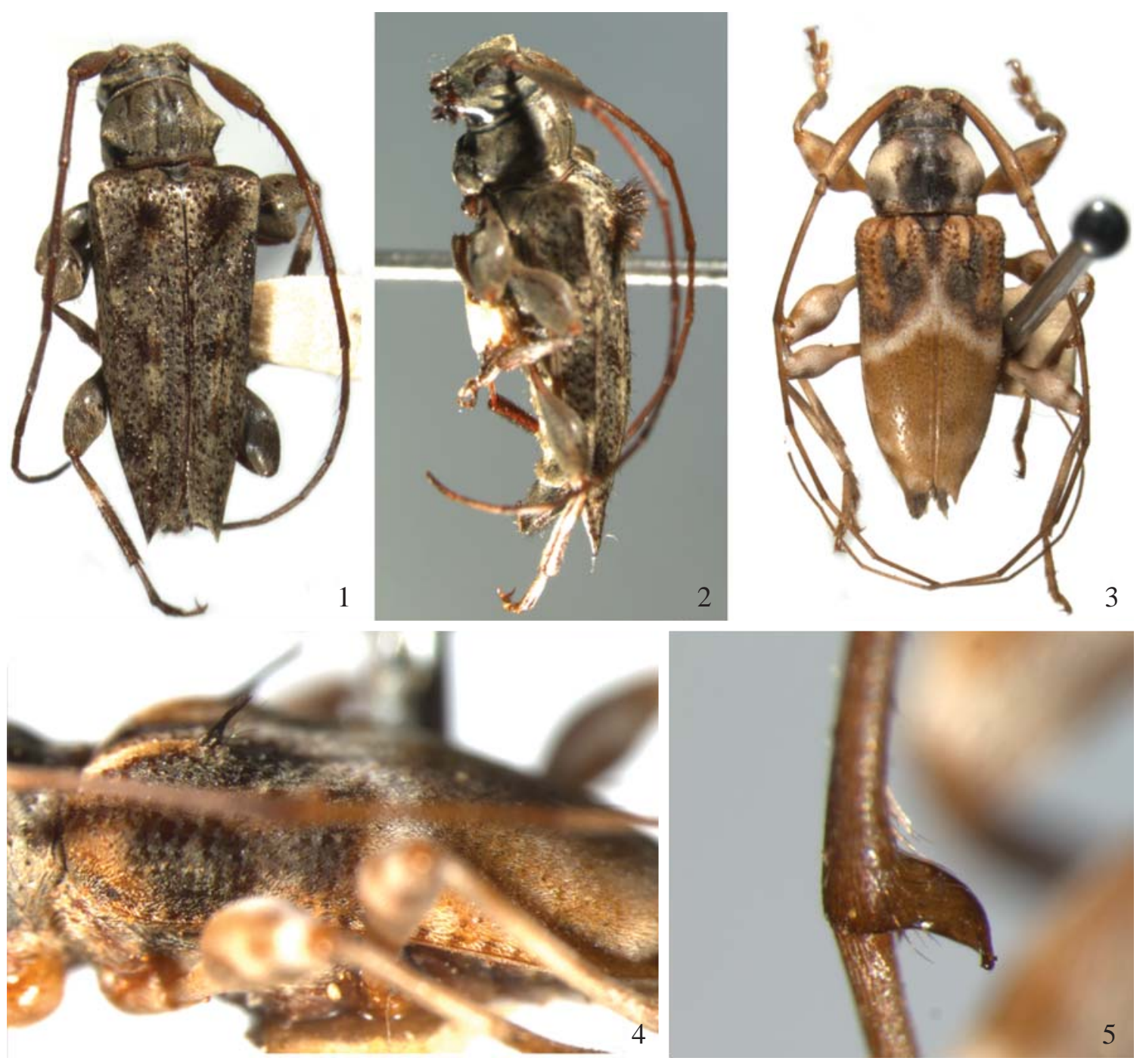

Figs. 1-5. 1, Tropidocoleus bicarinatus sp. nov., holótipo fêmea, vista dorsal, comprimento 12,0 mm; 2, Idem, vista lateral; 3, Odontozineus penicillatus sp. nov., holótipo macho, comprimento $10,0 \mathrm{~mm}$; Idem, vista lateral; 5, Idem, projeção dentiforme no antenômero III.

do protórax. Antenômero III uma vez e um quarto mais longo que o IV ou o escapo; antenômeros V-XI gradualmente mais curtos. Protórax com tubérculo lateral mediano, cônico e perpendicular ao eixo do corpo. Pronoto com duas bossas rasas, próximas à margem anterior. Processo prosternal muito estreito, aproximadamente 1/10 do diâmetro de uma procoxa; processo mesosternal com cerca de 1/5 do diâmetro de uma mesocoxa.

Élitros com cerdas eretas, curtas e esparsas. Crista centrobasal subarredondada, ornada com tufo de cerdas pretas eretas, moderadamente longas. Em cada élitro duas carenas longitudinais, a lateral, do úmero até o início do quarto distal e a dorsal do meio até o espinho distal externo. Ápices cortados em curva, ângulo interno com curta projeção romba e o externo projetado em espinho aguçado. Fêmures robustos, fortemente pedunculados e clavados. Tíbias anteriores recurvas. Primeiro metatarsômero uma vez e 1/3 mais longo que os seguintes reunidos. Últimos segmentos abdominais levemente entalhados.
Discussão. O grupo de gêneros com protórax com tubérculo lateral, élitros com cerdas eretas, com uma crista centro-basal e antenas e pernas sem pêlos longos abrange Baryssinus Bates, 1864, Neobaryssinus Monné \& Martins, 1976 e Lithargyrus Martins \& Monné, 1974. Parabaryssinus gen. nov. separa-se de Baryssinus e Neobaryssinus pelo protórax com tubérculo centro-lateral, os lados anterior e posteriormente ao tubérculo subparalelos e pelos élitros com carenas dorsal e lateral nitidamente demarcadas. Em Baryssinus e Neobaryssinus o protórax é arredondado lateralmente na metade anterior, e o tubérculo lateral prolongamento da respectiva curvatura e os élitros não têm carenas dorsais. Distingue-se de Lithargyrus pelos élitros sem grânulos nas carenas dorsais, pela presença de carena lateral e pela crista centro-basal provida de longos pêlos eretos. Em Lithargyrus os élitros apresentam carenas dorsais providas de grânulos setíferos, sem carena lateral e a crista centro-basal formada por escassos grânulos, sem pêlos longos no topo. 
Parabaryssinus lineaticollis (Gounelle, 1910), comb. nov. (Fig. 6)

Cleodoxus lineaticollis Gounelle, 1910: 17.

Baryssinus lineaticollis; Monné, 2001: 180, figs. 1, 2; 2005: 25 (cat.).

Macho. Tegumento castanho a castanho-escuro, avermelhado nos antenômeros II-XI. Pubescência predominantemente cinzento-acastanhada. Pubescência castanho-escura recobre quatro estreitas linhas longitudinais no pronoto, duas medianas e duas laterais; em cada élitro duas manchas dorsais pós-medianas, circundadas de pilosidade amarelada. As antenas alcançam os ápices dos élitros na extremidade distal do antenômero VIII, cerdas curtas, muito esparsas, nos antenômeros basais. Pontuação do pronoto restrita à fileira junto à margem posterior. Élitros gradualmente estreitados para extremidade. Pontuação moderadamente grosseira e densa em toda a superfície.

Dimensões em mm, macho. Comprimento total, 10,0; comprimento do protórax 2,0; maior largura do protórax, 2,0; comprimento do élitro,7,5; largura umeral, 3,0.

Material examinado. Colômbia, Cauca: 15 mi E Silvia (11000'), 16.VI.1970, macho, H. \& A. Howden col. (CNCI). Equador, [Carchi]: Tulcan, macho, 1901, Dr. G. Rivet (Holótipo, MNHN).

Discussão. Monné (2001) transferiu provisoriamente Cleodoxus lineaticollis para Baryssinus uma vez que os tubérculos laterais do protórax são medianos e existe carena longitudinal paralela à sutura na metade posterior dos élitros (vide discussão no gênero).

\section{Nyssodrysternum cingillum sp. nov}

(Fig. 7)

Etimologia. Cingillum = faixa, alusivo às faixas de pubescência cinzaesbranquiçada dos élitros.

Macho. Tegumento castanho-escuro; castanhoavermelhado nos antenômeros III a VII e na superfície dorsal dos fêmures. Pubescência de maneira geral castanho-escura. Pubescência cinza-esbranquiçada: linha mediana no occipício e mácula posterior aos lobos superiores dos olhos; no pronoto sete linhas longitudinais, uma mediana e três a cada lado do meio, a externa com o dobro da largura das internas; mancha mediana no escutelo; nos élitros com faixas transversais mediana e anteapical formadas por fileiras irregulares de manchas longitudinais entremeadas com pubescência castanho-escura, no quarto basal com linhas irregulares e pequenas máculas dispersas em toda a superfície. Lados do protórax recobertos com pilosidade densa uniforme.

As antenas alcançam as extremidades dos élitros no terço distal do antenômero VI. Tubérculos laterais do protórax rombos, situados no início do quarto posterior; pronoto sem tubérculos. Ápices dos élitros obliquamente truncados; pontuação moderadamente grossa e dispersa, restrita ao terço basal.
Processo prosternal levemente escavado em sentido longitudinal, com 1/3 da largura de uma procoxa; processo mesosternal plano, da mesma largura que uma mesocoxa. Metasterno com fina e densa pubescência acinzentada. Últimos urotergito e urosternito semicircularmente chanfrados, o último com os ângulos projetados em espinho curto.

Fêmea. As antenas atingem os ápices dos élitros na extremidade do antenômero VI; metasterno sem pubescência acinzentada; último urotergito ultrapassa em cerca de $1 \mathrm{~mm}$ os ápices dos élitros, extremidade transversalmente chanfrada; último urosternito truncado, ângulos não projetados.

Dimensões em mm, macho/fêmea. Comprimento total, 13,0/ 12,0-14,0; comprimento do protórax, 3,0/3,0-3,2; maior largura de protórax, 3,1/3,4-3,5; comprimento dos élitros, 8,0/7,0-9,0; largura umeral, 4,0/5,0-5,1.

Material-tipo. Holótipo macho, Bolívia, Santa Cruz: 4-6 km SSE Buena Vista (Hotel Flora \& Fauna), 2-12.II.2000, J. E. Wappes col. (MNKM). Parátipos, Bolívia, Santa Cruz: 3,7 km SSE Buena Vista (Hotel Flora \& Fauna), fêmea, 5-15.XI.2001, B. K. Dozier col. (MNRJ); fêmea, mesmos dados do holótipo, 1-15.XII.2002, R. Clarke col. (ACMT).

\section{Tropidozineus albidus sp. nov.}

(Fig. 8 )

Macho. Tegumento predominantemente castanho. Tegumento preto: ápice dos antenômeros III-X, escutelo, mancha pequena arredondada a cada lado do meio na metade anterior do pronoto; nos élitros: crista centro-basal, mancha grande pós-mediana, eqüidistante da margem e da sutura e máculas pequenas arredondadas, mais concentradas na metade distal; extremidade distal dos fêmures, das tíbias e dos tarsômeros.

Pubescência de maneira geral acinzentada. A pubescência branca recobre nos élitros uma grande mancha junto à sutura desde a região pós-escutelar até os ápices.

As antenas alcançam as extremidades dos élitros no ápice do antenômero V. Tubérculos laterais do protórax pósmedianos, com o ápice aguçado dirigido para os úmeros. Pronoto com três tubérculos rasos, dois arredondados na metade anterior revestidos de pubescência preta e um pósmediano longitudinal. Fileira de pontos junto às bordas anterior e posterior, unidas por fileiras longitudinal medianas centrais, a cada lado do tubérculo pós-mediano.

Élitros com crista centro-basal longitudinal, pouco proeminente, revestida de tufo de cerdas pretas semidecumbentes. Ápices cortados em curva, com espinho externo rombo. Pontuação fina e densa, mais evidente no terço basal.

Processo prosternal estreito, com cerca de $1 / 6$ do diâmetro de uma procoxa. Processo mesosternal plano, com aproximadamente $1 / 4$ do diâmetro de uma mesocoxa. Último urotergito arredondado no ápice; último urosternito semicircularmente emarginado. Fêmures alongados, a extremidade apical alcança as extremidades dos élitros. Metade distal das tíbias recoberta com densas cerdas pretas decumbentes. 

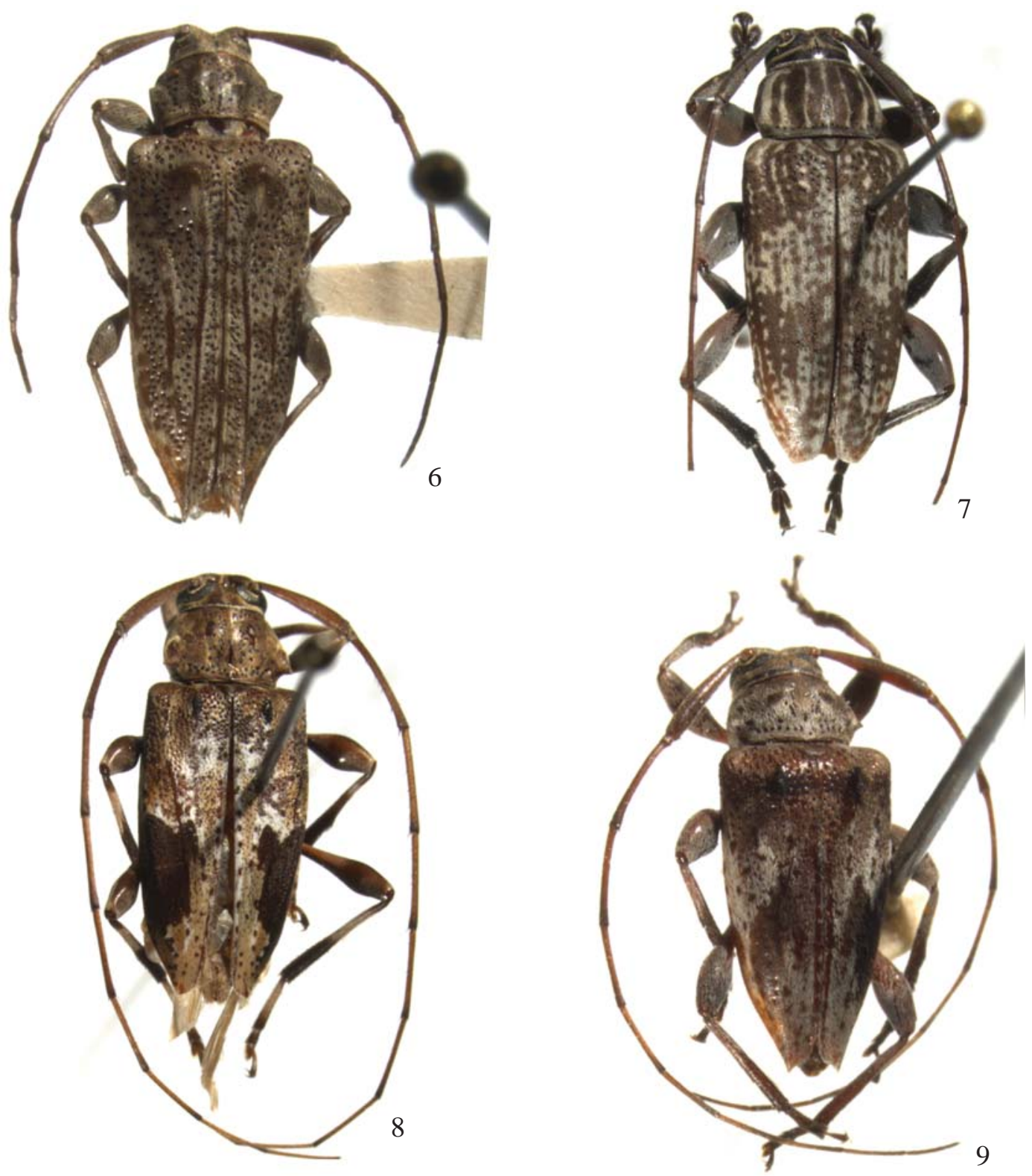

Figs. 6-9. 6, Parabaryssinus lineaticollis (Gounelle, 1910), comb. nov., macho, comprimento, 10,0 mm; 7, Nyssodrysternum cingillum sp. nov., holótipo macho, comprimento, 13,0; 8, Tropidozineus albidus sp. nov., parátipo fêmea, comprimento, 10,5 mm; 9, Tropidozineus martinsi sp. nov., holótipo macho, comprimento, $8,0 \mathrm{~mm}$.

Fêmea. As antenas alcançam as extremidades dos élitros no ápice do antenômero VI. Último urotergito arredondado, levemente entalhado no ápice; último urosternito semicircularmente entalhado.

Dimensões em mm, macho/fêmea. Comprimento total, 9,05/ 10,5; comprimento do protórax, 2,0/2,3; maior largura do protórax, 2,/0/2,2; comprimento do élitro, 7,0/7,7; largura umeral, $3,0 / 3,3$.

Material-tipo. Holótipo macho, Bolívia, Santa Cruz: 4-6 km SSE Buena Vista (Hotel Flora \& Fauna), 23-26.X.2000, Wappes \& Morris col (MNKM). Parátipos: mesma procedência do holótipo, fêmea, 212.II.2000, J. E. Wappes col. (MNRJ); fêmea, 15-22.XI.2001, M. C. Thomas \& B. K. Dozier (ACMT); macho, 15-20.XI.2003, R. Clarke col. (MNRJ); macho, 21-24.XI.2003, Wappes, Morris \& Nearns col. (ACMT).

Discussão. O gênero Tropidozineus Monné \& Martins, 1976 é composto por 15 espécies (Monné 2005), das quais $T$. argutulus Monné, 1988, T. impensus Monné \& Martins, 1976 e T. sincerus Monné, 1988 ocorrem na Amazônia (Amazonas e Rondônia). A espécie-tipo é Ozineus tersus Melzer, 1931 e não Ozineus torquatus Bates, 1881 como consta em Monné (2005). Pelo tegumento elitral ornado com grande mancha castanhoescura na metade distal, T. albidus Sp. nov., assemelha-se a $T$. impensus. Difere pelo extensão da mancha que não atinge a sutura e pelos ápices dos élitros cortados em curva e com 
espinho externo rombo. Em T. impensus a mancha castanhoescura ocupa a metade distal dos élitros da sutura até a margem e os ápices são transversalmente emarginados com os ângulos externo e sutural projetados em espinho aguçado curto.

\section{Tropidozineus martinsi sp. nov.}

$$
\text { (Fig. 9) }
$$

Etimologia. O nome específico é uma homenagem ao prezado colega Ubirajara R. Martins (MZSP).

Macho. Tegumento castanho-escuro. Pubescência predominantemente castanho-acinzentada. A pubescência preta recobre na metade anterior do pronoto, quatro máculas pequenas, arredondadas, e nos élitros faixa transversal de margens paralelas, no quarto basal, circundando as cristas centro-basais, sem alcançar a base. A pubescência castanha reveste faixa em ziguezague no terço distal dos élitros e fileiras longitudinais irregulares de pequenas máculas arredondadas.

As antenas alcançam o ápice dos élitros na extremidade distal do antenômero VI; com cerdas curtas, muito esparsas, na face ventral dos antenômeros I-IV e na extremidade apical dos antenômeros I-V. Protórax com tubérculo lateral aguçado na extremidade distal, ápice ligeiramente voltado para trás. Pronoto sem elevações; pontuação disposta junto à margem posterior e em duas fileiras longitudinais medianas; sem pontos junto à margem anterior.

Élitros com crista centro-basal subarredondada, ornada de denso tufo de cerdas pretas eretas. Carena lateral dos úmeros até o ângulo externo da extremidade distal; ápices obliquamente cortados, ângulo sutural não projetado o marginal prolongado em espinho aguçado.

Último urotergito arredondado; último urosternito subtruncado.

Fêmea. As antenas atingem as extremidades dos élitros no ápice do antenômero VII; últimos urotergito e urosternito truncados.

Dimensões em mm, macho/fêmea. Comprimento total, 8,0/ 10,2; comprimento do protórax, 1,5/1,8; maior largura do protórax, 1,2/2,3; comprimento do élitro,6,0/8,0; largura umeral, $4,0 / 5,0$.

Material-tipo. Holótipo macho, Brasil, Minas Gerais: Pedra Azul, $(700$ m), XI.1972, Seabra \& Oliveira col. (MNRJ). Parátipos: Bahia: Mun. Encruzilhada (Estrada Rio-Bahia, km 965, Motel da Divisa, 960 m), macho, X.1974, Seabra \& Roppa col. (MNRJ). Rio de Janeiro: Rio de Janeiro (Corcovado), fêmea, 18.X.1963, M. Alvarenga \& C. S. C. Seabra col. (MNRJ), mesma localidade e coletores, fêmea, 12.XII.1966, M. Alvarenga \& C. A. C. Seabra col. (MZSP), fêmea, 2.X.1972 (MNRJ), mesma localidade, fêmea, 1.X.1975, M. A. Monné \& C. A. C. Seabra col. (MNRJ), mesmos dados, fêmea, 24.X.1976 (MNRJ).

Discussão. Tropidozineus está representado no Sudeste e Sul do Brasil pelas espécies: T. amabilis Monné, 1991, T. cinctulus Monné \& Martins, 1976, T. fulveolus (Lameere, 1884), T. ignobilis (Bates, 1863), T. inexpectatus (Melzer, 1934), T. pauper (Melzer, 1931), T.quadricristatus (Melzer, 1935), T. rotundicollis (Bates, 1863), T. tersus (Melzer, 1931), T. tuberosus Monné, 1991 e T. vicinus (Melzer, 1931). Apenas T. cinctulus, T. tersus e T. martinsi sp. nov. apresentam faixa transversal de pubescência preta ou castanho-avermelhada no quarto basal dos élitros, circundando a crista centro-basal. T. martinsi $\mathbf{s p . ~ n o v . ~ s e p a r a - s e ~ d e ~} T$. cinctulus pela crista centrobasal subarredondada e ornada de tufo de cerdas pretas eretas; em $T$ cinctulus a crista é nitidamente longitudinal e sem cerdas pretas no topo. T. martinsi sp. nov. separa-se de T. tersus pelo colorido preto da faixa basal, que não alcança a margem anterior dos élitros, em T. tersus a faixa é castanho-avermelhada e ocupa todo o quarto basal dos élitros.

Agradecimentos. Ao Conselho Nacional de Desenvolvimento Científico e Tecnológico pelo auxílio Edital Universal No. 471726/ 2007-9, à Fundação Carlos Chagas Filho de Amparo à Pesquisa do Estado do Rio de Janeiro pelo auxílio No. E-26/110.716/2007, a James Wappes (ACMT) pela remessa de material; a Marcela Laura Monné (MNRJ) pela leitura crítica do manuscrito e pela execução das fotografias e tratamento digital.

\section{REFERENNCIAS}

Bates, H. W. 1863. Contributions to an insect fauna of the Amazon Valley. Coleoptera: Longicornes The Annals and Magazine of Natural History 12: 100-109.

Gounelle, E. 1910. Mission géodésique de 1'Equateur., Collections recueillis par le Dr. Rivet. Coleóptères: Cérambycides. Bulletin du Muséum National d'Histoire Naturelle 16: 15-19.

Monné, M. A. 2001. Sinopse dos gêneros de Acanthocinini neotropicais. II. Élitros sem setas, com crista centro-basal e carenas laterais (Coleoptera, Cerambycidae, Lamiinae). Iheringia, Zoologia 91: 177-181.

Monné, M. A. 2005. Catalogue of the Cerambycidae (Coleoptera) of the Neotropical Region. Part II. Subfamily Lamiinae. Zootaxa 1023: $1-759$.

Recebido em 15/07/2008; aceito em 27/12/2008 